\title{
GESTACIÓN POR SUSTITUCIÓN: LA DIGNIDAD HUMANA EN JUEGO
}

\author{
Gestational surrogacy: human dignity at stake
}

\author{
Antonio Arroyo Gil \\ Profesor Ayudante Doctor (acr. Titular) de Derecho constitucional \\ Universidad Autónoma de Madrid \\ antonio.arroyo@uam.es
}

http://dx.doi.org/10.18543/ed-68(2)-2020pp41-73

Recibido: 04.12.2020

Aceptado: 21.12.2020

\section{Resumen}

La gestación por sustitución ha planteado serios problemas de orden público en aquellos Estados en los que, como es el caso de España, esta práctica no se encuentra legalizada. La tensión existente entre la dignidad y los derechos de la mujer gestante, los deseos de los futuros padres comitentes y, sobre todo, el interés superior del menor no pueden resolverse de manera automática, atribuyendo, en todo caso, prioridad a este último. Antes bien, se requiere un análisis pormenorizado de cada caso en el que se tengan en cuenta todas las circunstancias concurrentes. Las respuestas a nivel estatal son difíciles e insatisfactorias. Idealmente, sería precisa una solución de Derecho internacional público.

\section{Palabras clave}

gestación por sustitución; gestación subrogada; maternidad subrogada; gestación para otros; vientres de alquiler; derechos fundamentales; orden público; interés superior del menor.

\section{Abstract}

Surrogate pregnancy has posed serious public order problems in those States where, as is the case in Spain, this practice is not legalised. The tension between the 
dignity and rights of pregnant women, the wishes of the future parents and, above all, the best interests of the child cannot be resolved automatically, with priority being given to the latter. Rather, a detailed analysis of each case is required, taking into account all the concurrent circumstances. Responses at state level are difficult and unsatisfactory. Ideally, a public international law solution would be required.

\section{Keywords}

surrogate pregnancy; surrogacy; surrogate motherhood; gestation for others; fundamental rights; public order; best interests of the child. 
Sumario: I. CONSIDERACIONES PRELIMINARES.1.1. La dificil determinación de un concepto. 1.2. La gestación por sustitución no es una técnica de reproducción humana asistida. 1.3. La tensión entre los derechos y los deseos. 1.4. La mutación del concepto de maternidad. 1.5. La naturaleza mercantil del contrato de gestación por sustitución. II. DigNIDAD HUMANA VERSUS AUTONOMÍA DE LA VOLUNTAD. III. DiFÍCILES CUESTIONES DE ORDEN PÚBLICO. IV. LA IMPOSIBILIDAD DE DISEÑAR UN CONTRATO DE GESTACIÓN POR SUSTITUCIÓN ACORDE A NUESTRO ORDEN CONSTITUCIONAL. V. LA NECESARIA RESPUESTA INTERNACIONAL Y EL (CONTROVERTIDO) INTERÉS SUPERIOR DEL MENOR. 5.1. Estados Unidos de América. 5.2. Francia. 5.3. Alemania. 5.4. Italia. 5.5. Portugal. 5.6. España. VI. Conclusiones. Bibliografía

\section{CONSIDERACIONES PRELIMINARES}

Antes de acometer de frente la cuestión de fondo a la que se tratará de dar respuesta en el presente trabajo, a saber, si cabría aceptar en España, de conformidad con el ordenamiento jurídico-constitucional vigente, la validez de un contrato como el de gestación por sustitución, diseñado de tal modo que quede garantizada la libertad de la mujer que toma la decisión de gestar para un tercero(s), lo que podría constituir condición suficiente para preservar asimismo su dignidad ${ }^{1}$, conviene que detengamos previamente la atención en algunas consideraciones que nos permitan contextualizar de manera suficiente de qué estamos realmente hablando cuando hablamos de gestación por sustitución $^{2}$. A ello se dedicarán, siquiera sea de manera meramente enunciativa, pues no hay espacio para un mayor detenimiento, los próximos epígrafes.

\section{La difícil determinación de un concepto}

En primer lugar, quizás convenga una aclaración terminológica. Bajo la expresión «gestación por sustitución» cabe entender aquella práctica, que en

1 Tal y como ha sido defendido desde determinados sectores políticos (el partido Ciudadanos, que el 27 de abril de 2017, en la XII legislatura, presentó una «Proposición de ley reguladora del derecho a la gestación por subrogación») y sociales (entre otras, la asociación Son Nuestros Hijos, la Asociación por la Gestación Subrogada en España, o la Agencia Española de Gestación Subrogada), con el aval de un relevante sector doctrinal (Presno y Jiménez: 2014; Atienza: 2015; Vela: 2015; Matia: 2019; etc.).

2 Javier Matia realiza un interesante resumen del (agrio, muchas veces) debate social y político sobre la gestación por sustitución, en el que pone de relieve cuáles son los principales argumentos de los llamados «abolicionistas» y de los «defensores» de esta práctica (Matia: 2019, 86 ss.). 
determinados países se encuentra legalizada por medio de contrato, en virtud de la cual una mujer se ofrece a gestar, con o sin aportación de su óvulo, para una persona individual (hombre o mujer) o una pareja (de distinto o del mismo sexo), conocidas como comitente/s, que puede/n aportar asimismo su/s gameto/s (o no), generalmente a cambio de una contraprestación económica, $\mathrm{o}$, al menos, de una compensación del mismo tipo, por las «molestias» y «gastos» que ello conlleva, y muy excepcionalmente de manera completamente altruista, a resultas de la cual dicha/s persona/s (comitente/s) acabará/n ostentando la paternidad y/o maternidad del recién nacido (Vilar: 2018, 30; Gómez Sánchez: 1994, 136).

Para hacer referencia a esta práctica contractual se han empleado diversos términos, a través de los cuales se manifiesta la conocida escasa inocencia o neutralidad (en el uso) del lenguaje: «gestación por sustitución», «gestación subrogada», «úteros o vientres de alquiler», «gestación para otro/s», etc. Quizás el que describa de manera más neutra la operación sea este último (Salazar: 2020, n. p. 2), pues, en efecto, el contenido principal de dicho contrato consiste exactamente en eso, en acordar la gestación de un bebé para otra/s persona/s que acabará/n ostentando la maternidad y/o paternidad del mismo, más allá de los muchos interrogantes que después haya que responder sobre la controvertida configuración y alcance del referido contrato.

No obstante, lo cierto es que el término que ha acabado generalizándose, al menos en España, es el de «gestación por sustitución» (Farnós: 2015, 30), porque es el que emplea la Ley 14/2006, de 26 de mayo, sobre Técnicas de Reproducción Humana Asistida (LTRHA), en cuyo artículo 10, bajo este mismo título («Gestación por sustitución»), se declara la nulidad de pleno derecho del referido contrato, en los términos siguientes:

«1. Será nulo de pleno derecho el contrato por el que se convenga la gestación, con o sin precio, a cargo de una mujer que renuncia a la filiación materna a favor del contratante o de un tercero.

2. La filiación de los hijos nacidos por gestación de sustitución será determinada por el parto.

3. Queda a salvo la posible acción de reclamación de la paternidad respecto del padre biológico, conforme a las reglas generales».

Por ese motivo, en el presente trabajo se hará referencia a ambos términos («gestación para otro/s» y «gestación por sustitución») de manera indistinta, evitando otros cuya carga axiológica (peyorativa, por lo común) parece mayor (Lamm: 2013).

\section{La gestación por sustitución no es una técnica de reproducción humana asistida}

Acto seguido interesa destacar que, si nos centramos en el caso español, que es el que va a ser aquí objeto principal de análisis, sin perjuicio de que 
también sea preciso, llegado el caso, hacer alguna referencia de carácter comparado, más allá de lo previsto en la citada LTRHA, esto es, que dicho contrato es nulo de pleno derecho ${ }^{3}$, quizás lo primero que convenga aclarar es que, en realidad, la gestación por sustitución no es una técnica de reproducción humana asistida (Valero: 2019, 425; Marrades: 2017, 231), equiparable a la fecundación in vitro, aunque desde determinados sectores se intente presentar así, porque aquí no es la mujer que desea ser madre la que se somete a un determinado tratamiento tendente a posibilitar su embarazo y ulterior maternidad, sino que, por el contrario, es un tercero, la mujer gestante, la que actúa como «mediadora» de la maternidad o paternidad de un tercero (mujer u hombre individual, o pareja, de distinto o del mismo sexo). Desde ese punto de vista, no parece, lógicamente, correcto concebir dicha práctica (acuerdo o contrato) como una técnica de reproducción humana asistida. Más bien nos encontramos ante un supuesto en el que intervienen diferentes personas, una/s con su deseo de ser madre/s y/o padre/s (los llamados comitentes), y otra con sus derechos constitucionalmente garantizados (la mujer gestante). De ahí que, con razón, se haya señalado que la gestación por sustitución es «un asunto de derechos fundamentales» (Valero: 2019).

\section{La tensión entre los derechos y los deseos}

Deseos y derechos, por consiguiente, andan en juego (Salazar: 2018). Ni que decir tiene, que, como es natural, son estos últimos (los derechos de la mujer gestante) los primeros que ha de preservar el ordenamiento jurídico ${ }^{4} ; \mathrm{y}$ solo cuando ello esté plenamente garantizado (si es que puede llegar a estarlo), el poder público se podrá plantear la conveniencia de posibilitar a

${ }^{3}$ Sobre si dicha nulidad del contrato de gestación por sustitución conlleva también una prohibición de celebración de los mismos, dadas las consecuencias sancionatorias de carácter penal (arts. 220.2 y 221.1 y $2 \mathrm{CPl}$ ) y administrativo que su práctica tiene en España, ha habido una ardua discusión entre la doctrina científica. Así, mientras autores como Susana Quicios eran de esa opinión (Quicios: 2019, 7 ss.), para otra parte de la doctrina científica, destacadamente Manuel Atienza, no cabe equiparar nulidad de pleno derecho con prohibición: «la gestación por sustitución no está prohibida en nuestros Derecho; (...) esa práctica no contradice ningún principio moral racionalmente justificado ni tampoco los valores y principios de la Constitución española, de manera que no podría entenderse que fuera en contra del orden público español» (Atienza: 2006; y 2015).

${ }^{4}$ Resulta, a tal efecto, muy oportuna la observación de Octavio Salazar acerca de la necesidad de que el debate sobre la gestación para otro/s «ha de situarse en una 'fase' previa a la existencia misma del menor, por lo que entiendo que los argumentos esenciales son los que tienen en cuenta los derechos de la gestante, aunque es evidente que posteriormente el contrato tendrá determinados efectos en el niño o niña que nazca» (Salazar: 2020,8). 
través de esta vía la satisfacción de aquellos deseos (de la/s mujer/es y/o del/ de los hombre/s que desean ser madre/s y/o padre/s).

Es importante tener en cuenta este punto de partida, porque es más que discutible, en efecto, que la libertad reproductiva, tal y como ha sido entendida por el Tribunal Constitucional (TC) español, el Tribunal Europeo de Derechos Humanos (TEDH) y el Tribunal de Justicia de la Unión Europea (TJUE), se pueda identificar con el llamado «derecho a tener hijos» (o a procrear), del que quepa derivar directamente la necesidad u obligación del Estado de permitir y regular los contratos de gestación por sustitución (Díaz Crego: 2020; Simón: 2020, 17; Valero: 2019, 426) . Más bien, nos encontramos, como se señalaba con anterioridad, en presencia de un mero deseo -o interés- individual, por más legítimo que sea, cuya conversión en derecho quedaría, entonces, a la libre decisión del legislador ${ }^{6}$, siempre y cuando quede despejada la duda primera y primordial: la compatibilidad de tal eventual reconocimiento con el propio orden constitucional (del que el orden público forma parte).

Más en concreto, lo que habría que comprobar es si dicho contrato de gestación por sustitución se podría configurar de tal forma que resultase plenamente respetuoso con la libertad y dignidad de la mujer gestante, o, de manera más específica, con todos los derechos que a la misma reconoce y garantiza ya el ordenamiento jurídico-constitucional. Y ello sin perjuicio, claro está, de que en caso de acabar aceptándose la regulación de esta práctica su contenido deba también garantizar, con carácter prioritario, los superiores intereses del menor.

${ }^{5}$ No es esa la opinión de Antonio J. Vela, para quien la gestación por sustitución favorece la maternidad y/o paternidad «como reflejo del derecho fundamental a la procreación y a la constitución de una familia» (Vela: 2015, 128). Sin embargo, no se puede confundir el derecho a acudir a las técnicas de reproducción humana asistida que el legislador español ha regulado por entenderlas conformes con el orden constitucional, con el deseo de que también se considere así una práctica que, como hemos visto, no cabe encuadrar entre dichas técnicas reproductivas, y que, además, resulta difícilmente compatible, por no decir directamente incompatible, con nuestro orden público, como veremos más adelante.

${ }^{6}$ Es eso lo que explica que el Tribunal Constitucional español haya considerado la libertad reproductiva como una manifestación de la autonomía de la voluntad, y no como un derecho fundamental autónomo, que solo será invocable ante la jurisdicción ordinaria «según su particular configuración legal» (ATC40/2017, de 28 de febrero -FJ 5). Y en la misma línea, el TEDH, si bien ha reconocido en el ámbito del derecho a la vida privada del art. $8 \mathrm{CEDH}$ el respeto a la decisión de ser padre/madre, en tanto que protección de la identidad individual y la autonomía personal (STEDH Evans c. Reino Unido, de 10 de abril de 2007), y la consiguiente obligación de los Estados parte de actuar normativamente en consecuencia, proporcionando tal protección (STEDH V. C. c. Eslovaquia, de 8 de noviembre de 2011), en ningún caso ha entendido que de ahí quepa derivar una obligación para aquellos de legalizar la gestación por sustitución (Díaz Crego: 2020, 16). 


\section{La mutación del concepto de maternidad}

La gestación para otro/s, de admitirse, conllevaría un cambio radical en el concepto de maternidad, que ya no quedaría necesariamente determinada por razón del parto (mater semper certa est), tal y como sucede en la vigente legislación española, y en la de otros muchos Estados en los que esta práctica está también prohibida, o es nula de pleno derecho, como es el caso de Francia, Alemania o Italia (Vilar: 2019, 817). A partir de su reconocimiento cabría diferenciar entre maternidad gestacional (por gestar al futuro hijo), maternidad genética (por la aportación de gametos femeninos) y maternidad jurídica (por la atribución de la función jurídico-social de madre), pudiéndose atribuir estas funciones a diferentes mujeres, lo que obligaría a determinar qué maternidad prevalece a la hora de establecer la filiación (Lamm: 2013, 31; Farnós: 2015, 9)7.

\section{La naturaleza mercantil del contrato de gestación por sustitución}

La gestación para otro/s tiene una clara base contractual, que se asemeja mucho al contrato de compraventa, en tanto que supone, en la mayor parte de los lugares en donde tal práctica es aceptada, la gestación, parto y entrega del niño nacido, normalmente, a cambio de una contraprestación económica (o, en su caso, de una compensación del mismo tipo por los «perjuicios»o «molestias» causados por el embarazo y el parto). También se ha equiparado al contrato de obra, en tanto que el resultado que se busca es el hijo que se encarga mediante un previo acuerdo, generalmente económico (Díaz Romero: 2010, 1).

Tanto en un caso como en otro la gestación por sustitución supone la introducción en el tráfico comercial de funciones genuinamente humanas -en este caso, solo de las mujeres (la capacidad de gestar)- e, incluso, de seres humanos (en formación). Por lo que se refiere a las primeras, no parece convincente el intento de desgajar la función (la gestación propiamente dicha) de la persona (la mujer que gesta), como si de la realización de un mero trabajo autónomo se tratara (Salazar: 2020,12). Y por lo que afecta a los segundos, los argumentos a su favor deberían ser válidos para justificar por qué no se debería legalizar también la compraventa de niños ya nacidos, pues salvando

7 Según Silvia Vilar, «la filiación ya no constituye únicamente un vínculo individual entre el niño y cada uno de sus progenitores, sino que, al mismo tiempo, circunscribe al menor en una familia y en un cierto orden social, por lo que el Derecho debería posibilitar, frente a la verdad biológica, configurar jurídicamente la voluntad como vínculo que otorgue efectos relacionados con el parentesco - al igual que sucede en los supuestos de adopción-, excluyendo el principio de indisponibilidad que suele regir en esta materia» (Vilar: 2019, 818). 
las distancias, tanto en una operación como en otra lo que, en último término, se cuestiona es si un ser humano (en formación o ya nacido) puede ser objeto de un contrato en el que a cambio de una contraprestación (o compensación) económica se determina a quién corresponde su maternidad y/o paternidad (con todas las demás garantías añadidas que se quiera).

\section{DIGNIDAD HUMANA VERSUS AUTONOMÍA DE LA VOLUNTAD}

Se ha defendido que las objeciones formuladas con anterioridad se salvarían, en buena medida, si en los contratos de gestación para otro/s no hubiese intercambio económico alguno ${ }^{8}$ (cosa que, dicho sea de paso, no sucede, salvo de manera absolutamente excepcional, en aquellos países en que dicha práctica se encuentra legalizada). Sin embargo, no parece que la cuestión sea tan sencilla, pues incluso aceptando dicha posibilidad (puro altruismo en sentido estricto), la gran cuestión de fondo quedaría pendiente de respuesta, a saber: si el contrato de gestación por sustitución, por su propia naturaleza, es conforme, o no, con la dignidad humana (de la mujer gestante).

Quienes están a favor de la legalización de la gestación por sustitución defienden, como principal argumento, que cada mujer ha de ser libre para decidir si quiere, o no, gestar un niño para otra persona. Por resumirlo brevemente: para los partidarios de la legalización de esta práctica sería una cuestión de «autonomía de la voluntad», de forma que la prohibición de la misma -se llega a decir- sería lo que, en realidad, atentaría contra la dignidad de la mujer (gestante), en la medida en que se le privaría de su capacidad de autodeterminación personal (Lamm: 2013; Atienza: 2015; Vela: 2015; Vilar: 2018; de Lora: 2018). Dicho de otro modo, si el Estado prohibiese tal práctica estaría adoptando un rol paternalista que resultaría contrario a la dignidad de la mujer (Presno y Jiménez: 2014, 9 ss.), en la medida en que se negaría a esta su capacidad de decidir sobre qué hacer con su propio cuerpo (o con las funciones biológicas que este es capaz de desarrollar, en este caso, la capacidad de gestar). Un argumento, por cierto, que, como recuerdan estos autores, en otras ocasiones ha sido esgrimido, en sentido contrario, para defender el reconocimiento del derecho a la interrupción voluntaria del embarazo.

Sin entrar en las radicales diferencias que existen entre ambas cuestiones (gestación por sustitución y aborto), este argumento (el de la autonomía de la voluntad), justo es reconocerlo, tiene un gran peso, ya que, en el fondo, su

${ }^{8}$ El profesor Matia se manifiesta a favor de una posición intermedia entre quienes defiende la libertad contractual plena para convenir el precio y el puro altruismo (Matia: 2019, 116). 
defensa no es sino una manifestación de la defensa de la libertad personal o del libre desarrollo de la personalidad, cualidades inherentes a una persona, que jurídico-constitucionalmente gozan de una gran protección en nuestro ordenamiento (como valores o principios: arts. 1 y $10.1 \mathrm{CE}$ ). Sin embargo, tampoco se puede ignorar que pese a esa protección constitucional, la autonomía de la voluntad ni es un derecho fundamental ni tiene, como es lógico, un carácter ilimitado o absoluto. En un Estado democrático de Derecho, como lo es el español, el poder público puede imponer límites a esa autonomía de la voluntad. Límites que vendrán determinados por el respeto, en primerísimo lugar, a los derechos fundamentales y libertades públicas, así como a otros bienes constitucionalmente protegidos. De hecho, esa es una de las funciones principales del Derecho: poner límites a la autonomía de la voluntad de cada individuo mediante el establecimiento de normas de conducta y prohibitivas que no son sino el reflejo de los valores, principios y derechos que el propio ordenamiento jurídico reconoce y garantiza, como modo de preservar, entre otras cosas, la paz social y la dignidad humana. En tal sentido cabe entender el contenido del art. 1255 Código civil cuando dispone que «[1] os contratantes pueden establecer los pactos, cláusulas y condiciones que tengan por conveniente, siempre que no sean contrarios a las leyes, a la moral ni al orden público».

Entre esos valores, principios y derechos fundamentales constitucionalmente reconocidos y protegidos, se encuentran, en efecto, la «dignidad de la persona» y los «derechos individuales que le son inherentes» (art. 10.1 CE), punto del que debe partir toda reflexión sobre la gestación para otro/s (Balaguer: 2017, 29 ss.). De acuerdo con esta fórmula, cabe entender, en buena lógica, que ningún derecho puede contradecir la dignidad humana; antes bien, todos ellos son una proyección de ese «valor espiritual y moral inherente a la persona» (STC 53/1985, de 11 de abril), constituyendo, por tanto, manifestaciones concretas de su contenido, cuya limitación no podrá conllevar ningún «menosprecio para la estima que, en cuanto ser humano, merece la persona» (STC 120/1990, de 27 de junio). Así sucede, indudablemente, con los derechos fundamentales, y así debe de suceder, con más razón, con los demás derechos que el legislador, estatal o autonómico, reconozca, como proyección directa y derivada, respectivamente, de dicha dignidad, y a cuya luz unos y otros han de ser interpretados (Gómez Sánchez: 2005, 226).

La diferencia entre los derechos fundamentales y los derechos legales es, valga la redundancia, fundamental, pues mientras que no cabe duda alguna de que los primeros no contradicen la dignidad humana, sino que, por el contrario, la dotan de contenido concreto, en el caso de los segundos, sin embargo, sí puede existir esa duda, de ahí que haya que contrastar exhaustivamente el contenido del derecho legal que se quiera reconocer con el contenido constitucional de la dignidad humana. 
Sobre lo que sea la dignidad humana, más allá de su reflejo en los derechos fundamentales y demás bienes constitucionalmente reconocidos, se ha debatido largo y tendido, sin que haya sido posible llegar a un acuerdo generalmente aceptado (Chueca: 2015, 25 ss.; Veronesi: 2015, 123 ss.; Elvira: 2015 , 199). No obstante, sí suele admitirse -al menos, desde Kant, con la segunda formulación del imperativo categórico- que una de las manifestaciones de esa dignidad humana pasa por tratar a toda persona como un fin en sí mismo, y no solamente como un mero medio o instrumento para conseguir otro fin (Atienza: 2015). Lo que cabría predicar no solo de terceros sino también de la propia persona, que en ejercicio de su libertad no podría, por ejemplo, renunciar voluntariamente a esta convirtiéndose en esclavo de otra persona (Marrades: 2017, 234).

De igual modo, tampoco sería conforme a la dignidad humana la cosificación de una persona (o - cabría añadir- de sus funciones más genuinamente humanas, como lo es, en el caso de las mujeres, la capacidad de gestar), lo que, entre otras cosas, repugnaría la idea de introducir a esa persona (o sus funciones) en el tráfico comercial como objeto de un contrato, siquiera fuese gratuitamente, en tanto que se trataría de res extra commercium, tal y como en el ordenamiento jurídico español prevé el art. 1271 Código civil (Valero: 2019, 427).

En esta línea, el TC español expresamente ha señalado que el respeto a la dignidad humana conlleva la prohibición de instrumentalizar o patrimonializar a una persona (STC 53/1985), o considerarla como un objeto de mercado (STC 224/1999); prohibición esta última que se extiende al cuerpo y al material biológico humano (SSTC 212/1996 y 166/1999). A mayor abundamiento, el propio Tribunal ha reconocido que en la concreción del principio de dignidad humana la radical igualdad de todas las personas no es óbice para que puedan ser tenidas singularmente en cuenta determinadas circunstancias, como la condición de mujer o la maternidad (STC 53/1985).

En este punto, tampoco se ha de ignorar la relevancia que puede tener el «contexto relacional» (económico, social, cultural) en el que se encuentran muchas mujeres, que, dado el caso, podría generar serias dudas sobre la existencia de una voluntad verdaderamente libre y autónoma para la firma de un contrato de unas características tan «singulares» como son las propias del contrato de gestación para otro/s (Rodríguez: 2013; Salazar: 2017, 105; y 2020).

Pues bien, a partir de estas consideraciones, la cuestión clave a la que responder sería la siguiente: "¿la gestación subrogada es un atentado contra la dignidad de la mujer gestante, o su libre voluntad de prestarse al proceso impide considerarlo un atentado a su dignidad?» (Arroyo: 2017) O, dicho de otra forma: ¿hay algo «indigno» en ese contrato de gestación por sustitución que ni siquiera la autonomía de la voluntad de la persona afectada, la mujer gestante, puede vencer? 
Creo que sí lo hay. De acuerdo con el ordenamiento jurídico-constitucional español, en el contrato de gestación para otro/s hay un derecho fundamental que claramente se pone en riesgo: la integridad física, y, en su caso, moral, de la mujer gestante (art. 15.1 CE); derecho que, según el TC español, se encuentra especialmente vinculado a la dignidad humana. Cuando una mujer firma ese contrato y lo pone en práctica está poniendo su cuerpo (o, incluso, su vida) en riesgo, dado que la gestación y parto de un niño conllevan, per se, ciertos riesgos (Marrades: 2017, 228-229); y, en todo caso, tal embarazo y gestación traen consigo una indudable afectación del cuerpo de la mujer, sujeto a importantes transformaciones, que pueden ser no solo físicas, sino también de carácter psicológico o mental. Y todo ello se hace no con el propósito de ejercer su propia libertad reproductiva, lo que sería suficiente para que tales riesgos resultaran perfectamente asumibles, sino con el fin último de satisfacer el deseo de un tercero que, por muy legítimo que este sea, no deja de ser eso: un deseo (no un derecho). Pues bien, me parece que una «operación» de este calibre representa un claro atentado contra el orden público, sobre todo, cuando se hace a cambio de una contraprestación o compensación económica, que inevitablemente pone en cuestión el elemento volitivo de la supuesta libertad que se ejerce por parte de la mujer gestante.

En apoyo de esta posición encontramos diversas resoluciones de organismos internacionales contrarios también a la gestación por sustitución por considerarla atentatoria contra la dignidad humana de la mujer gestante y del menor. Así, por ejemplo, la Declaración de 2012 del Consejo de Europa, y el ulterior rechazo, el 15 de marzo de 2016, por su Comisión de Asuntos Sociales y de Salud a la propuesta del Informe Sutter, favorable a la gestación por sustitución; o la Resolución de 17 de diciembre de 2015 del Parlamento Europeo sobre el Informe anual sobre los derechos humanos y la democracia en el mundo 2014, en el que «[c] ondena la práctica de la gestación por sustitución, que es contraria a la dignidad humana de la mujer, ya que su cuerpo y sus funciones reproductivas se utilizan como una materia prima; estima que debe prohibirse esta práctica, que implica la explotación de las funciones reproductivas y la utilización del cuerpo con fines financieros o de otro tipo, en particular en el caso de las mujeres vulnerables en los países en desarrollo, y pide que se examine con carácter de urgencia en el marco de los instrumentos de derechos humanos». En sentido similar, y ya a nivel nacional, un organismo consultivo independiente como el Comité de Bioética de España, en su «Informe sobre los aspectos éticos y jurídicos de la maternidad subrogada», de 16 de mayo de 2017, llega a la conclusión de que «existen sólidas razones para rechazar la maternidad subrogada», siendo la fundamental la explotación de la mujer gestante.

Pese a todo, imaginemos, sin embargo, que el legislador puede legalizar la gestación por sustitución, porque se entienda que ello no es contrario al 
orden público, en la medida en que las barreras que este impone han sido vencidas por la autonomía de la voluntad de la mujer gestante. Pues bien, aun en ese caso, en los contratos de gestación por sustitución al uso (esto es, en los que media intercambio económico) hay otro derecho (que también es principio y valor) que se encuentra asimismo en cuestión: el de la igualdad (Ruiz-Rico: 2017, 66 ss.). Y es que el legislador no puede legalizar una práctica como la de la gestación para otro/s, que acaba por concretarse en la posibilidad de que una persona o pareja pueda acabar ostentando la paternidad/ maternidad sobre un niño, si no se garantiza al mismo tiempo que todas las personas, que reúnan ciertas condiciones, pero con independencia de su capacidad económica, pueden acceder a ella. Porque lo contrario supondría que la capacidad de tener hijos a través de esta práctica estaría reservada únicamente a personas con elevado poder adquisitivo. Dicho de otra forma, aquí lo que estaría en riesgo es la igual consideración que merece todo ser humano, es decir, la igual dignidad de todos los seres humanos, incompatible con una especie de ciudadanía censitaria derivada de la capacidad económica, que resultaría determinante en un aspecto tan relevante como lo es el del acceso a la maternidad/paternidad.

En relación, además, con el principio de igualdad, se ha de tener presente que, si media contraprestación económica, casi inevitablemente se estará introduciendo, de manera -en mi opinión- contraria al orden público, una capacidad del cuerpo de la mujer (la de gestar) en el tráfico comercial, basada en una situación de desigualdad: la de la mujer gestante (que precisa ese dinero) y la del padre y/o madre comitente/s (que dispone/n de ese dinero). Esta situación de desigualdad, derivada de una capacidad biológica y una necesidad económica ${ }^{9}$, por un lado, y de un deseo acompañado de alta capacidad económica, por el otro, resulta contraria a todo entendimiento posible de la igualdad constitucionalmente garantizada, tanto en sentido formal (art. $14 \mathrm{CE}$ ) como material (art. 9.2 CE).

Pues bien, a partir de este razonamiento cabría preguntarse si es posible legalizar la gestación por sustitución, siempre y cuando la misma sea absolutamente altruista ${ }^{10}$. Y toda vez que se acepte que la primera objeción (afecta-

${ }^{9}$ La Oficina Permanente de la Conferencia de la Haya de Derecho Internacional Privado ha alertado sobre «el vínculo entre el aumento de la gestación por sustitución trasnacional en ciertos países, normalmente con economías emergentes, y la existencia de bolsas de mujeres pobres que se prestaban a gestar para otros, normalmente de países mucho más ricos» (Díaz y Pérez-Moneo: 2020, 2 ss.). Vid.: «A preliminary report on the issues arising from international surrogacy arrangements «, Preliminary Document No 10 of March 2012 for the attention of the Council of April 2012 on General Affairs and Policy of the Conference, p. 7 .

${ }^{10}$ No se puede ignorar, sin embargo, que tal y como se ha constatado, es fácil establecer la gratuidad del contrato en la letra del mismo, pero en la práctica va a ser mucho más 
ción a la dignidad de la gestante) ha quedado vencida gracias al libre consentimiento expresado por la mujer gestante.

La cuestión, por tanto, queda planteada en sus desnudos términos de esta manera. Sin embargo, antes de tratar de darle una respuesta, resulta preciso tener en cuenta que el contrato de gestación por sustitución al uso tiene otros contenidos que, como veremos seguidamente, difícilmente resisten un mínimo contraste con nuestro orden público.

\section{III.DIFÍCILES CUESTIONES DE ORDEN PÚBLICO}

Son muchas, en efectos, las cuestiones que surgen a la hora de analizar el contenido concreto de los contratos de gestación por sustitución y su posible (in)compatibilidad con el orden público español -o con un más genérico «bien común» (Simón: 2020). Por poner solo algún ejemplo, centrémonos en las siguientes, que, por lo general, suelen formar parte de los mismos, y cuya sola formulación, a modo de pregunta, denota la dificultad de acomodar el contenido característico de estos contratos y la cláusula de orden público:

- ¿Se puede obligar a la mujer gestante a que renuncie a la maternidad meses antes de que se produzca el parto? Y, en caso afirmativo, ¿debe de tener algún tipo de consecuencias su posible «arrepentimiento»?

Me parece que en este punto se pone muy claramente de relieve que hay algo en la naturaleza de este contrato de gestación por sustitución (al menos, tal y como suele estar configurado en la mayor parte de los Estados en que esta práctica se encuentra legalizada) que inevitablemente atenta contra la dignidad humana, al tiempo que genera una gran inseguridad jurídica. Y es que si no queremos privar a la mujer gestante de un derecho tan fundamental como es el de su libertad de elección sobre su maternidad, directamente vinculado al libre desarrollo de su personalidad (art. 10.1 CE), y, en definitiva, inescindiblemente vinculado con el núcleo duro de su dignidad, hay que aceptar que la mujer gestante, durante su embarazo, en cualquier momento, e incluso hasta un tiempo después del parto, puede cambiar de opinión, sin que ello tenga por qué suponerle un grave perjuicio de carácter personal o económico. Porque no es de extrañar que los lazos afectivos que se puedan generar entre la madre gestante y el embrión vayan creciendo según avanza el embarazo $^{11}$. Por eso, la pretensión de petrificar en un momento dado, meses antes

difícil controlar si, en efecto, no ha mediado algún tipo de contraprestación o compensación económica (Brunet: 2013).

11 Tal y como tuvo ocasión de señalar el TC de Portugal en su Sentencia nº 225/2018, de 24 de abril. 
del parto, la decisión de la mujer gestante a este respecto, supone convertir a esta, junto al feto en formación, en un mero objeto del contrato, en una cosa.

- ¿Se puede obligar a la mujer gestante a que lleve determinado régimen de vida? ¿Son lícitas las técnicas psicológica tendente a "preparar» a la mujer para que no sienta apego por el embrión que está gestando?

Por razones similares a las expresadas anteriormente, tampoco parece que se pueda condicionar la libertad, valor superior de nuestro ordenamiento jurídico (at. 1.1 CE), y, más en concreto, el libre desarrollo de la personalidad (art. 10.1 CE), a través de un contrato de este tipo, que puede acabar suponiendo para la mujer gestante el sometimiento a un estilo o régimen de vida muy estricto, impuesto por el/los comitente/s (o, como es lo habitual, por las agencias que intermedian en este tipo de contratos).

Menos aún defendibles parecen las sesiones de psicoterapia destinadas a evitar que la mujer gestante desarrolle sentimientos de afecto o apego por el embrión que está gestando, como sucede, por ejemplo, en Estados Unidos o en India (Salazar: 2020, 28 ss.), y que en España bien podrían considerarse propias de un trato inhumano o degradante prohibido por el art. 15.1 CE.

- ¿Qué sucede si el feto viene con malformaciones? ¿Se ha de otorgar a los padres comitentes el «derecho» a renunciar a la paternidad? En tal caso, si el embarazo sigue adelante, ¿ha de asumir la mujer gestante la maternidad del niño? ¿O acaso los comitentes pueden «obligar» a la mujer gestante a abortar?

Tampoco merece la pena detenerse mucho en esto, porque salta a la vista su posible contradicción con nuestro orden público, en la medida en que nos encontremos, como podría ser el caso, con una posición discrepante entre los comitentes (renuncia a la maternidad/paternidad) y la mujer gestante (deseo de llevar a término el embarazo). No cabe imaginar mayor cosificación de un ser humano (aunque esté en formación) que la que se podría dar en un supuesto como este: si el embrión es un producto «perfecto», como el que podrían desear los comitentes, el embarazo puede continuar sin problema; pero si presenta alguna «tara», los comitentes pueden renunciar a él, pese a que la mujer gestante desee seguir a término con su embarazo. Naturalmente, podría configurarse de tal modo el contrato que los comitentes, en todo caso, asuman la maternidad/paternidad, con independencia del estado en el que venga el bebé, y siempre y cuando no lleguen a un acuerdo con la mujer gestante sobre la posible interrupción del embarazo. Pero la perversidad de ese acuerdo radica en la posibilidad que ofrece: cabría imaginar que una mujer podría decidir abortar si el feto viniese con alguna malformación en el caso 
de que la maternidad le correspondiese a ella, pero, por el contrario, podría decidir seguir adelante con el contrato a sabiendas de que ella no será la madre del futuro bebé. Tampoco cuesta mucho imaginar que no serán muchas las personas (futuros comitentes) que estarán dispuestas a firmar un contrato en tales condiciones.

Evidentemente, hay muchas más cuestiones problemáticas que pueden surgir en el seno de una relación contractual de gestación por sustitución, pero me parece que estas son suficientemente significativas como para dejar constancia de que el contenido de este contrato, tal y como hoy en día se está practicando en muchos lugares, además de generar una gran inseguridad jurídica, es manifiestamente contrario a nuestro orden público, más que nada porque, de un modo u otro, acaba colocando a la mujer gestante en una posición instrumental, cuando no desemboca directamente en su cosificación.

\section{IV.LA IMPOSIBILIDAD DE DISEÑAR UN CONTRATO DE GESTACIÓN POR SUSTITUCIÓN ACORDE A NUESTRO ORDEN CONSTITUCIONAL}

Así las cosas, cabría, sin embargo, preguntarse si es posible diseñar un contrato de gestación por sustitución que cumpla con las condiciones que aquí se han apuntado: altruismo; plena libertad de la mujer gestante para decidir cómo llevar a cabo su gestación, incluida la posibilidad de arrepentimiento sobre la renuncia a la maternidad hasta un tiempo después del parto; continuación del embarazo y atribución de la maternidad/paternidad a los comitentes, aun cuando el feto presente alguna malformación si es que la mujer gestante no decide abortar, etc. ${ }^{12}$.

Más allá de otras consideraciones, un tipo de contrato como ese, con toda probabilidad, va a resultar difícilmente viable, en la medida en que será

12 Javier Matia, en una línea similar, aunque desde una perspectiva completamente opuesta (pues, a diferencia de lo que aquí se sostiene, entiende que «no toda regulación de la gestación subrogada resulta incompatible con la dignidad de la mujer»), realiza algunas sugerencias sobre una posible (y deseable) regulación futura de esta práctica, de modo que se consiga una legítima «integración de intereses» de todas las partes involucradas (Matia: 2019, 89 y 115 ss.). En un sentido similar, Antonia Durán, sostiene que «para que no se perpetúe la esquizofrenia jurídica que ahora existe, sería recomendable introducir una regulación específica en nuestro Derecho material sobre la gestación por sustitución», de acuerdo con determinadas premisas, «buscando la mejor manera para acomodar los derechos de todas las partes que intervienen en el proceso, pero poniendo el acento en la necesidad de garantizar por encima de todo el interés superior del menor» (Durán: 2019, 581-582). También Octavio Salazar señala cuáles son los extremos que una propuesta garantista de la gestación por sustitución debería tener presentes (Salazar: 2017, 108-113). 
prácticamente imposible encontrar mujeres que se ofrezcan a gestar para un tercero $^{13}$, y personas deseosas de ser madres o padres que se arriesguen a iniciar un proceso de estas características en el que no gozan de ninguna garantía sobre el resultado final.

Pese a todo, procuremos situarnos en el mejor de los escenarios posibles e imaginemos que pueden existir mujeres que, de manera absolutamente libre (si es que se puede hablar en estos términos), sin intercambio económico alguno, y con todas las garantías adicionales que hemos señalado, deciden acordar mediante contrato la gestación para un tercero, que tras el parto acabará asumiendo la maternidad y/o paternidad del nacido. ¿Sería constitucionalmente admisible en España un contrato de esas características?

Sigo pensando que no, porque incluso bajo esas estrictas condiciones la dignidad de la mujer gestante quedaría en entredicho de conformidad con nuestro ordenamiento jurídico, que no puede tolerar -a mi juicio- un contrato que, en último término, supone poner (una capacidad de) un cuerpo humano, aunque sea de manera libre y voluntaria, al servicio de la satisfacción del deseo de un tercero. Sin restar relevancia a todo lo dicho más arriba, creo que la clave que explica y justifica dicha negativa a la aceptación de este tipo de contratos por ser contrarios a nuestro orden público se encuentra en el hecho mismo de que se permita celebrar un contrato que, por definición, supone tomar una decisión anticipada sobre una función (la gestación) que, por desarrollarse en el cuerpo de una mujer, puede acabar cambiando completamente la percepción inicial de esta sobre la maternidad del recién nacido. Y sostener que este problema se podría resolver mediante el reconocimiento a favor de la mujer gestante de la posibilidad de arrepentimiento sin perjuicio alguno (de carácter económico), es tanto como afirmar el sinsentido de este contrato: ¿qué valor tiene un contrato si una de las partes puede acabar tomando una decisión contraria al contenido y finalidad del mismo sin consecuencia alguna para ella?

${ }^{13}$ Como señala Ana Valero, «es significativo el caso de Reino Unido, donde se da la paradoja de que, a pesar de permitir la subrogación altruista, es el país europeo que se encuentra a la cabeza en la contratación de mujeres para dicho fin en el extranjero, principalmente en India, Tailandia y, en menor medida en Estados Unidos», lo que «evidencia que la 'maternidad altruista' es un mito que legitima y encubre el auténtico negocio a nivel mundial -principalmente para los agentes intermediarios-que supone la mercantilización del cuerpo humano de mujeres en clara situación de necesidad económica y social» (Valero: 2019, 427). Por su parte, Ana Marrades apunta el caso de Canadá, en «donde es legal pero 'altruista' (...) aun así se está pagando una cantidad nada desdeñable por 'gastos derivados del embarazo': alrededor de 22.000 dólares canadienses (...). En total todo el proceso cuesta entre 60.000 y 80.000 euros» (Marrades: 2017, 224). 


\section{LA NECESARIA RESPUESTA INTERNACIONAL Y EL (CONTROVERTIDO) INTERÉS SUPERIOR DEL MENOR}

Negada del modo en que hemos visto la posibilidad de diseñar un contrato de gestación por sustitución que resulte acorde con nuestro orden constitucional, hemos de ser conscientes de que el problema, sin embargo, no está completamente resuelto. Simple y llanamente porque es un problema que no admite fácilmente una solución estatal o nacional, sino que, por el contrario, demanda, idealmente, una respuesta de alcance superior, de Derecho internacional privado, que hoy por hoy no existe.

$\mathrm{Y}$ es que, en efecto, de lo que se trata ahora es de responder a la preguntar de qué sucede con aquellas situaciones en que un hombre, una mujer o una pareja llevan a cabo un proceso de gestación por sustitución en otro país, en donde esta práctica se encuentra reconocida, y después pretenden que el niño así habido sea inscrito en España como hijo suyo ${ }^{14}$.

Antes de conocer cuál ha sido la solución adoptada en nuestro país, interesa ofrecer una panorámica general sobre cómo se ha afrontado esta misma cuestión en otros países de nuestro entorno, y, a propósito de ello, conocer también cuál ha sido la vacilante postura del Tribunal Europeo de Derechos Humanos (TEDH) al respecto.

Como comprobaremos seguidamente, por regla general, el criterio del interés superior del menor (reconocido en los arts. 3.1 y 7.1 de la Convención de la ONU sobre los Derechos del Niño, de 20 de noviembre de 1989, que en el ámbito del Convenio de Roma de 4 de noviembre de 1950 se reflejaría en la protección que el art. 8 ofrece al derecho a la vida privada ${ }^{15}$, y en el orden constitucional español en las previsiones de los apartados 2, 3 y 4 del art. 39 $\mathrm{CE}$ ) ha desempeñado un papel muy relevante (Benavente: 2020, $10 \mathrm{ss}$.).

Por su parte, el TEDH no ha ofrecido una respuesta clara a este respecto, al entender que no existe un consenso amplio en este sentido, lo que le ha llevado a optar porque sean los propios Estados los que regulen esta cuestión en

${ }^{14}$ Pese a la dificultad de precisar el número exactos de niños nacidos como consecuencia de un proceso de gestación por sustitución que residen en España, según el Gobierno, entre 2010 y 2016 fueron 979 las inscripciones realizadas. No obstante, las asociaciones de familias y las agencias partidarias de esta práctica calculan que cada año nacen entre 800 y 1.000 hijos de padres españoles con este método (fuente: El País - 8 de noviembre de 2017: https://elpais.com/politica/2017/11/08/actualidad/1510169780_776827. html).

${ }^{15} \mathrm{La}$ apertura interpretativa que ofrece el art. $8 \mathrm{CEDH}$ es bien conocida, «en buena medida por el diferente contenido de la protección de los derechos equiparables reconocidos por la legislación interna de los Estados miembros y también por la multitud de situaciones que pueden acogerse bajo ese enunciado. De esta forma, el art. 8 se ha convertido en cajón de sastre donde tienen cabida las situaciones más dispares» (Elvira: 2015, 214). 
función de cuál sea su orden constitucional y, en definitiva, a tenor de su propia concepción del orden público (margen de apreciación estatal). Sobre lo que sí se ha pronunciado es sobre la necesidad de que la filiación derivada de este tipo de contratos sea eficaz en un Estado parte, a fin de garantizar la protección del derecho a la vida privada de los menores y el derecho a la vida familiar (Carmona y Redondo: 2020).

Es decir, a partir de las condiciones que establece el art. 8.2 CEDH (que exista una previsión legal y que la medida sea necesaria, en una sociedad democrática, para la seguridad nacional, la seguridad pública, el bienestar económico del país, la defensa del orden y la prevención del delito, la protección de la salud o de la moral, o la protección de los derechos y las libertades de los demás), un Estado podría alegar motivadamente la excepción de orden público internacional si considerase que la eficacia de este tipo de contratos vulnera alguno de esos bienes, principios y/o derechos y libertades que constituyen el fundamento de su ordenamiento jurídico.

En el juicio de proporcionalidad que se llevase a efecto habrían de ponderarse los diferentes intereses en conflicto (el general del Estado en defensa de dichos bienes, principios o derechos, y el particular de los comitentes en defensa del reconocimiento de la filiación del menor y su consiguiente inscripción en el registro correspondiente). Va de suyo que el TEDH habría de tener muy en cuenta la eventual lesión de los derechos a la vida privada y a la identidad del menor que se pudiera derivar de la inseguridad jurídica generada por el hecho de estar viviendo con una/s persona/s que legalmente no está/n reconocida/s como su/s madre/s y/o padre/s, con los perjuicios que además ello podría tener en otros ámbitos como, por ejemplo, el sucesorio. Y es que la inscripción registral establece una presunción iuris tantum de exactitud y legalidad de los hechos inscritos, permitiendo, en este caso, a los que figuran como madre/s y/o padre/s mostrar a su hijo como tal a todos los efectos legales. Por tanto, no solo es un mecanismo para dejar constancia, sino también una vía para acceder al conjunto de derechos y obligaciones que se derivan de la filiación.

\section{Estados Unidos de América}

Algunos estados de los EE.UU. fueron de los primeros en legalizar la gestación para otro/s, durante los últimos años de la década de los ochenta de la pasada centuria. Fue la Corte Suprema de New Jersey la que en el célebre caso Baby M, resuelto el 3 de febrero de 1988, confirmó la paternidad por parte de un matrimonio incapaz de procrear de un bebé habido como consecuencia de un contrato de gestación por sustitución, en el que el marido aportó su material genético, y la mujer gestante su óvulo. Producido el parto y entregado el menor a los comitentes, la mujer gestante reclamó su 
maternidad biológica, iniciándose así un proceso judicial, en el que, en primera instancia, el tribunal de New Jersey confirmó que los padres comitentes ostentaban legítimamente la custodia del menor, en tanto en cuanto dicho contrato de gestación por sustitución había sido válido. Recurrida la sentencia en apelación, la Corte Suprema de New Jersey sostuvo, sin embargo, que ese acuerdo era «ilegal e inejecutable», de modo que la custodia había de decidirse atendiendo no a dicho contrato, sino al interés superior del menor, fallando, a tal efecto, que la misma correspondía a los padres comitentes, si bien reconoció a la mujer gestante derechos de visita (Simón: 2017, 3).

En un caso casi simultáneo (In re Marriage of Buzzanka), un tribunal de primera instancia de California decidió que la menor habida como consecuencia de un contrato de gestación por sustitución, en el que ninguno de los comitentes había aportado material genético, y que se habían divorciado antes del parto, carecía de padres legales. Recurrida la sentencia, la Corte de Apelaciones de California revisó el caso y falló, el 10 de marzo de 1988, que dicha declaración de orfandad legal era contraria al orden público, de modo que, pese a no haber aportación genética alguna, los comitentes debían ser considerados los responsables y padres legales de la menor (Simón: 2017, 4).

Aunque existen diferencias notables entre unos estados (en los que esta práctica está prohibida) y otros (en los que se admite, si bien con diferencias importantes en cuanto al contenido de su regulación), California es, precisamente, uno de los lugares a los que más se acude para llevar a cabo este proceso por parte de quienes tienen recursos económicos suficientes, dado el carácter comercial del contrato de gestación por sustitución. La razón no es otra que la legislación especialmente garantista de la posición de los padres y/o madres comitentes, así como la intervención judicial durante el proceso, lo que da lugar a que dichos contratos sean después plenamente ejecutables en el país de origen de aquellos, si bien se echa en falta una mayor protección de los derechos de la mujer gestante y de los menores nacidos a raíz de la formalización del susodicho contrato (Úbeda: 2020).

\section{Francia}

En este país, la gestación por sustitución se encuentra prohibida y sancionada penalmente. Ya en 1990 la Corte de Casación declaró que la gestación por sustitución se oponía al «principio de indisponibilidad del cuerpo humano» y que, en consecuencia, era contraria al orden público. En la misma línea, el Consejo de Estado entendió en 2009 que existían diversos motivos que justificaban la prohibición de esta práctica (interés superior del menor; protección de la mujer gestante; evitar la mercantilización del menor y del cuerpo de la mujer gestante, etc.). Sin embargo, el 25 de enero de 2013 el Ministerio de Justicia dictó una circular instando a los jueces a conceder 
certificados de nacionalidad a favor de aquellos menores nacidos en el extranjero, sin que sirva de pretexto para hacerlo la sospecha de que se haya recurrido a esta práctica. La circular fue confirmada por el Consejo de Estado el 12 de diciembre de 2014 (Simón: 2017, 12-13).

Más recientemente, la Corte de Casación, a resultas de la jurisprudencia del TEDH a la que nos referiremos a continuación, ha reconocido que si uno de los comitentes ostenta la paternidad biológica del bebé nacido en otro país en el que la gestación por sustitución es una práctica legal podrá ver reconocida su filiación en Francia, y su pareja podrá obtener la paternidad adoptiva (Alcaraz: 2020; Matia: 2019, 89 ss.).

En Francia, el primer caso de gestación por sustitución con importante repercusión judicial y mediática, y que acabó desembocando en sendas sentencias del TEDH, fue el de los Sres. Mennesson y Labassée (Sentencia de 26 de junio de 2014). En ambos supuestos, los recurrentes eran un matrimonio que, después de haber intentado en diversas ocasiones sin éxito la fecundación in vitro, decidieron acudir a California para formalizar un contrato de gestación por sustitución. Tanto en un caso como en el otro, una donante ajena a la pareja había aportado sus óvulos para que fueran fecundados con semen de cada uno de los respectivos maridos. A resultas de ello nacieron tres bebés (un niño de la primera pareja y dos gemelas de la segunda). El problema se planteó a la hora de inscribir dichos niños como hijos de los comitentes en el registro civil francés, dado que se pretendía que la maternidad/ paternidad de los mismos fuera reconocida a partir de la celebración de un contrato (de gestación por sustitución) que suponía una violación del orden público francés. A tal efecto, la negativa de la Corte de Casación francesa fue clara al señalar que tal inscripción no era posible, pues lo contrario significaría validar un contrato contrario al ordenamiento francés.

Ante el cerrojazo judicial nacional, los Sres. Mennesson y Labassée decidieron acudir al TEDH, el cual, en su Sentencia de 26 de junio de 2014, condenó a Francia por vulnerar el derecho a la vida privada de los menores, reconocido en el art. 8 CEDH. Según el TEDH, la decisión de las autoridades francesas colocaba a los niños en una situación de inseguridad jurídica en relación con su estatus familiar (nacionalidad, herencia, etc.), lo que suponía una vulneración de su identidad y, en definitiva, de su derecho a la vida privada, amparado por el art. 8 CEDH (Simón: 2017, 15-17).

En consecuencia, el Tribunal de Estrasburgo obligó al Estado francés a que reconociera la filiación y consecuente inscripción registral del menor habido como consecuencia de un contrato de gestación por sustitución en un país extranjero siempre que el mismo tuviera vinculación genética con el padre comitente. Nada se dijo respecto de la filiación de la mujer comitente (o del otro hombre, en el caso de parejas del mismo sexo, que no aporta material genético alguno), remitiéndose tan solo a la posibilidad de la adopción, 
lo que resulta muy cuestionable desde la perspectiva del principio de igualdad (Matia: 2019, 97). Cuestión esta que se ha visto en parte resuelta con motivo del Dictamen de 10 de abril de 2019 emitido por el TEDH a resultas de una Opinión consultiva planteada por el Tribunal de Casación francés. En ella, el TEDH sostiene la necesidad de que el derecho interno (francés, en este caso), en los casos en que un niño haya nacido como consecuencia de un proceso de gestación por sustitución, «ofrezca una posibilidad de reconocimiento de un vínculo de filiación entre este niño y la madre de intención», especialmente cuando esta ha aportada sus gametos, en tanto que exigencia derivada del respeto a la vida privada del menor. No obstante, tal reconocimiento puede llevarse a efecto como el Estado francés considere preciso de acuerdo con su derecho interno (inscripción de filiación o adopción).

Resulta también interesante destacar que en la referida Sentencia de 26 de junio de 2014 el TEDH entendió que, pese a lo dicho, no se podía considerar que los Sres. Mennesson y Labassée hubieran visto vulnerado su derecho a la vida privada y familiar, no solo porque no se les había impedido la convivencia de hecho con sus hijos, sino, además, porque la negativa del Estado francés a su inscripción derivaba, antes que nada, de la prohibición legal que existe en ese país de este tipo de prácticas. Y, en consecuencia, el TEDH entendió que en este caso nos encontramos, de nuevo, ante una cuestión de orden público respecto de la cual los Estados gozan de un amplio margen de apreciación ${ }^{16}$.

\section{Alemania}

En Alemania el contrato de gestación por sustitución está también prohibido y sancionado. Sin embargo, en relación con la inscripción registral de los niños obtenidos por gestación para otro/s en un país donde esta práctica está permitida, la jurisprudencia dio un giro relevante a finales de 2014. En una Sentencia de 10 de diciembre de 2014, la máxima instancia judicial en el orden civil, el Bundesgerichtshof, validó por vez primera una decisión judicial extranjera ordenando la inscripción de la paternidad a favor de los comitentes, una pareja de hombres que había acudido a California para contratar

${ }^{16}$ A partir de esta condena, el Tribunal de Casación francés realizó un cambio de jurisprudencia, y así, en junio de 2015 aprobó la inscripción en el registro civil de dos niños concebidos por gestación subrogada en Rusia. No obstante, este cambio no afectó a la situación judicial en que se encontraban los padres comitentes, que habían sido juzgados antes de este cambio jurisprudencial. La cuestión llegó de nuevo al TEDH, que volvió a condenar a Francia, aplicando la misma doctrina: violación del derecho a la vida privada del menor reconocido en el art. $8 \mathrm{CEDH}$ (casos Bouvet y Foulon c. Francia, Sentencia 21 de julio de 2016; y Karine Laborie c. Francia, de 19 de enero de 2017). 
estos servicios, pese a que, en un principio, las autoridades administrativas alemanas habían denegado la inscripción del bebé como hijo de los comitentes por razones de orden público. El alto tribunal alemán, en una sentencia muy discutida de 10 de diciembre de 2014, afirmó que «el reconocimiento en el extranjero de la paternidad a los comitentes en un contrato de maternidad subrogada no habría de reputarse en sí mismo contrario al orden público, siempre que uno de los comitentes fuese padre genético del niño» (Simón: 2017, 12).

En una sentencia posterior, de 20 de marzo de 2019, en atención al hecho de que tanto la madre como el padre comitentes habían aportado su material genético (óvulo y espermatozoides), el Tribunal reconoce la paternidad biológica del hombre, pero no así la de la mujer por ser ello contrario a la previsión del art. 1591 del Código civil alemán, que establece la maternidad por parto, invitando a aquella a que proceda, dado el caso, a adoptar al menor (Redondo: 2020).

\section{Italia}

Si bien la gestación por sustitución se encuentra prohibida y penalmente sancionada en Italia, lo cierto es que las situaciones derivadas del hecho de que haya habido nacionales italianos que han acudido al extranjero amparándose en su legislación permisiva de este tipo de contratos, con la intención de registrar después a esos menores como hijos suyos en Italia, ha complicado extraordinariamente el panorama, sobre todo, tras la intervención del TEDH (Alberti: 2020).

En el conocido caso Paradiso Campanelli c. Italia, un tribunal italiano decidió que un niño nacido en Ucrania fuera separado de los padres comitentes y entregado en adopción a otra familia, por entender que la paternidad de aquellos traía causa de un contrato de gestación por sustitución, inválido en este país. El caso llegó al TEDH, que, mediante Sentencia de la Sección 2a, de 27 de enero de 2015, condenó a Italia por vulneración del derecho a la vida privada reconocido en el art. $8 \mathrm{CEDH}$, debido a la falta de proporcionalidad en la medida adoptada por el tribunal nacional, que iba en perjuicio del interés superior del menor.

No obstante, el TEDH entendió que las medidas adoptadas por las autoridades italianas cumplían con el test de proporcionalidad, en tanto que se encontraban previstas en la ley, traían causa de un previo incumplimiento de la normativa sobre adopción y reproducción asistida, perseguían una finalidad lícita, como es la defensa del orden público, y buscaban proteger y garantizar los derechos del menor (Simón: 2017, 17-20).

En definitiva, pese al sentido condenatorio de la sentencia (cinco votos frente a dos), el TEDH admitió que las autoridades italianas habían actuado 
en todo momento dentro del marco legal, en tanto que, al no poderse determinar la nacionalidad del niño, debido a que se desconocía la procedencia de los gametos, «la aplicación del Derecho italiano por parte de los tribunales nacionales, que llevó a la constatación del estado de abandono del menor, no podría considerarse arbitraria».

Esta controvertida resolución fue recurrida ante la Gran Sala, que la revocó el 24 de enero de 2017 (por once votos contra seis), en una sentencia en la que el TEDH, sin perder de vista la necesaria protección de los niños (de todos, en general), acordó privar a los comitentes italianos de la paternidad del menor, debido a que este no tenía vínculo genético con ninguno de ellos y en tanto que la convivencia había durado tan solo ocho meses (dos en Rusia y seis en Italia).

A través de esta relevante sentencia ${ }^{17}$, parece derivarse, por consiguiente, que cuando el TEDH acude al criterio del interés superior del menor para decidir sobre la regularización de algún supuesto de gestación por sustitución, ha de tener presente no solo el interés del niño en cuestión, sino el de todos los niños en general, basando el núcleo de su argumentación en la existencia de un vínculo biológico entre el menor y, al menos, alguno de los comitentes, y en el período de tiempo durante el que se ha prolongado la convivencia entre todos ellos. Pero su postura no queda tan clara en aquellos otros casos en que no hay aportación de material genético alguno por parte de los comitentes y la convivencia familiar no ha sido muy prolongada en el tiempo. En definitiva, seguimos careciendo de criterios claros que ofrezcan seguridad jurídica para este tipo de prácticas. Si bien, al menos, queda claro a partir de esta última sentencia de $2017 \mathrm{del}$ caso Paradiso Campanelli c. Italia que los comitentes no pueden pretender la aplicación automática de un principio (el del interés superior del menor) para que su Estado les reconozca la inscripción de la filiación, ni el propio Estado puede acudir automáticamente a otro principio (el del orden público internacional) para negar dicha inscripción.

\section{Portugal}

En Portugal la gestación por sustitución es concebida como una técnica de reproducción humana asistida por la Ley 25/2016. No obstante, el Consejo Nacional de Procreación Médicamente Asistida, autoridad responsable en la materia, que controla todo el proceso, correspondiéndole incluso la autorización del propio contrato, en un Decreto de 2017 precisó que la

${ }^{17}$ Es posible encontrar múltiples comentarios de estas sentencias. Valga por todos: Farnós (2017); y Ruiz (2019). 
gestación por sustitución, pese a requerir de técnicas de reproducción humana asistida, no es, en sí misma, una técnica de reproducción humana asistida.

La Ley 25/2016 reconoce que la gestación por sustitución (de carácter altruista) está al servicio de las mujeres que no pueden gestar, sin que, por tanto, el hombre por sí solo, o la pareja de hombres, pueda/n acceder a la misma. Esta ley, que concibe esta práctica como un contrato, no como un derecho, procura dispensar una amplia protección a la mujer gestante, pero deja a los niños habidos en el marco de la misma desprovistos del derecho a investigar su identidad genética, y tampoco regula la situación en que se encuentran aquellos que procedan de otro país en el que también se encuentre legalizado dicho contrato.

El 24 de abril de 2018, el TC portugués anuló varios preceptos de esta ley, en vigor desde agosto de 2017, sin que dicha anulación sea aplicable a los procesos de gestación ya autorizados por el Consejo Nacional. El Tribunal considera que, en sí misma, la ley no viola ni la dignidad de la mujer gestante ni la del bebé nacido mediante este práctica, al tiempo que tampoco cuestiona el deber del Estado de protección de la infancia; sin embargo, sí contiene -en opinión del TC-determinadas disposiciones que suponen una contradicción con ciertos «principios y derechos fundamentales consagrados en la Constitución».

Así, entre otras cosas, el Alto Tribunal ha censurado que no exista la posibilidad de que la gestante se arrepienta, lo que impide «el ejercicio pleno de su derecho fundamental al desarrollo de la personalidad». También ha criticado la «indeterminación excesiva» de la ley en lo que se refiere a los límites que se imponen a las partes del contrato, lo que en la práctica supone que se pueden realizar negociaciones sobre las condiciones del embarazo que podrían resultar a todas luces excesivas. Asimismo, el Tribunal ha censurado el hecho de que se mantenga de cara al futuro bebé tanto el anonimato de los donantes de óvulos o espermatozoides como el de la mujer gestante, al entender que ello supone «una restricción innecesaria a los derechos de identidad personal y al desarrollo de la personalidad» de las personas nacidas como consecuencia de un contrato de gestación por sustitución (Gómez Fernández: 2020).

\section{España}

En España, pese a que, como sabemos ya, de acuerdo con el art. 10 de la Ley 14/2006, de 26 de mayo, sobre técnicas de reproducción humana asistida, el contrato de gestación por sustitución es nulo de pleno derecho, hay personas, a las que no les es posible tener un hijo mediante un proceso de gestación natural, que acuden a otros países en los que la gestación para 
otro/s se encuentra legalizada o tolerada, y que vuelven a España con la intención de inscribir a ese bebé en el Registro Civil como hija/o suyo.

Para dar respuesta a uno de esos numerosos casos en que se dificultaba tal inscripción registral, la Dirección General de Registros y Notariado (DGRN) dictó una primera Resolución, de 18 de febrero de 2009, en la que se ordenaba la inscripción en el Registro civil consular español en Los Ángeles (California) de dos bebés nacidos como consecuencia de un contrato de gestación por sustitución, en tanto hubiera, como era el caso, una certificación registral (del estado de California, en este caso) que determinase la filiación de uno de los comitentes españoles. Impugnada por el Ministerio Fiscal, el Juzgado de Primera Instancia $n^{\circ} 15$ de valencia, en su sentencia núm. 193/2010, de 15 de septiembre, negó la validez de la misma por entender que esa práctica era nula de pleno derecho en el ordenamiento jurídico español.

Acto seguido, el 5 de octubre de 2010, la DGRN aprobó una nueva Instrucción a través de la cual se permite la inscripción de relaciones de filiación de niños nacidos en el extranjero por gestación por sustitución, si bien se introducen algunas condiciones más agravadas: siempre que se presente la resolución judicial del tribunal competente extranjero que determine la filiación, así como el exequátur de dicha resolución, bajo la condición de que esta no sea fruto de un procedimiento de jurisdicción voluntaria, sino de un proceso contencioso, y en tanto la mujer gestante haya actuado de manera libre y consciente (Vilar: 2019, 819-820; Salazar: 2017, 89-91).

Poco después de un año, el 23 de noviembre de 2011, la Audiencia Provincial de Valencia -sección 10a- dictó una sentencia (núm. 826/2011) que resolvía el recurso interpuesto contra la del Juzgado de Primera instancia, en la que se reafirmó en la idea de que el contrato de gestación por sustitución es nulo de pleno derecho, y, en consecuencia, no tiene cabida en nuestro ordenamiento la pretensión de inscribir la filiación de un niño nacido en un país extranjero en el que sí está permitida esta práctica, mediante la apelación al argumento del interés superior del menor.

Recurrida ante el Tribunal Supremo (TS), este (sección 10 a de la Sala de lo civil), unos años más tarde, en la sentencia núm. 835/2013, de 6 de febrero de 2014, ratificada mediante Auto de 2 de febrero de 2015, volvió a negar la inscripción en el Registro civil de la filiación de los dos menores nacidos en California como consecuencia de un contrato de gestación por sustitución, pese a que en el documento expedido por las autoridades californianas se atribuía la paternidad a la pareja de hombres españoles, al entender que dicho contrato es nulo de pleno derecho por ser contrario al orden público internacional español, «entendido básicamente como el sistema de derechos y libertades individuales garantizados en la Constitución y en los convenios internacionales de derechos humanos ratificados por España, y los valores y 
principios que estos encarnan». Concretamente, el TS entendió que el registro en España debe someterse a un control de orden público, categoría de la que forman parte principios constitucionales básicos como la dignidad humana y el libre desarrollo de la personalidad (art. 10.1 CE), así como el mandato de protección de la familia y los hijos (art. $39 \mathrm{CE})^{18}$.

Según el Tribunal, «en nuestro ordenamiento jurídico y en la mayoría de los países con ordenamientos basados en similares principios y valores, no se acepta que la generalización de la adopción, incluso internacional, y los avances en las técnicas de reproducción humana asistida vulneren la dignidad de la mujer gestante y del niño, mercantilizando la gestación y la filiación, 'cosificando' a la mujer gestante y al niño, permitiendo a determinados intermediarios realizar negocio con ellos, posibilitando la explotación del estado de necesidad en que se encuentran mujeres jóvenes en situación de pobreza y creando una especie de 'ciudadanía censitaria' en la que sólo quienes disponen de elevados recursos económicos pueden establecer relaciones paterno-filiales vedadas a la mayoría de la población» (FD Tercero.6).

Además, el TS, cuestiona la apelación al «interés superior del menor» como argumento a favor de la inscripción registral, puesto que ello «debería llevar a admitir la determinación de la filiación a favor de personas de países desarrollados, en buena situación económica, que hubieran conseguido les fuera entregado un niño procedente de familias desestructuradas o de entornos problemáticos de zonas depauperadas, cualquiera que hubiera sido el medio por el que lo hubieran conseguido, puesto que el interés superior del menor justificaría su integración en una familia en buena posición y que estuviera interesada en él» (FD Quinto.5).

De este modo, el TS español trata de establecer ciertos límites al «fácil» argumento del interés superior del menor, apelando a un orden público, cuya finalidad es, entre otras, evitar actuaciones que puedan suponer una vulneración de la dignidad de la mujer (gestante) y de los menores nacidos mediante esta práctica de la gestación por sustitución, válida en otros países, pero nula de pleno derecho en España.

En palabras del propio TS: «Es cierto que el no reconocimiento de la filiación establecida en la inscripción registral de California puede suponer un

${ }_{18}$ Desde determinadas posiciones doctrinales, esta sentencia ha sido muy criticada, en la línea del Voto particular formulado a la misma, por entender que en estos supuestos nos encontramos ante un mero problema de reconocimiento de la validez de una resolución de un Estado extranjero, que ha determinado la paternidad de los comitentes de acuerdo con su ordenamiento jurídico; no se trataría, por tanto, de decidir, de nuevo, sobre la filiación, de acuerdo con la identificación de la ley que se considere aplicable al fondo del asunto (Calvo y Carrascosa: 2015). 
perjuicio para la posición jurídica de los menores ${ }^{19}$. Pero no puede olvidarse que el establecimiento de una filiación que contradiga los criterios previstos en la ley para su determinación supone también un perjuicio para el menor. Y que la mercantilización que supone que la filiación de un menor resulte determinada, a favor de quien realiza el encargo, por la celebración de un contrato para su gestación, atenta contra la dignidad del menor al convertirlo en objeto del tráfico mercantil» (FD Quinto.8).

$\mathrm{Y}$ ante la alegación de los recurrentes acerca de la situación de desprotección en que podrían quedar los menores si no se les reconociera la inscripción de filiación, el TS recuerda que existen en nuestro ordenamiento jurídico diversas instituciones que permiten ofrecer una respuesta a tales situaciones: «El propio art. 10 de la Ley de Técnicas de Reproducción Humana Asistida, en su párrafo tercero, permite la reclamación de la paternidad respecto del padre biológico, por lo que si alguno de los recurrentes lo fuera, podría determinarse la filiación paterna respecto del mismo. Asimismo, figuras jurídicas como el acogimiento familiar o la adopción permiten la formalización jurídica de la integración real de los menores en tal núcleo familiar» (FD Quinto.11).

Esta sentencia del TS deja, por tanto, sin efecto la referida Instrucción de la DGRN, de 5 de octubre de 2010. Sin embargo, de manera difícilmente comprensible, la propia DGRN emitió una Circular el 11 de julio de 2014 mediante la que autorizaba a los cónsules españoles a seguir aplicando la controvertida Instrucción de 2010. De esta forma, la Administración, de modo ciertamente incomprensible, parece haber decidido ignorar el «sometimiento pleno a la ley y al Derecho» que le impone el artículo 103.1 de la Constitución. Más tarde, la DGRN dictó una Instrucción de 14 de febrero de 2019, que permite la inscripción en el Registro civil siempre que al menos uno de los padres comitentes haya aportado material genético. Pero la misma fue dejada sin efecto inmediatamente, mediante una Instrucción de la misma DGRN de 18 de febrero (a resulta de un previo comunicado emitido por el Ministerio de Justicia el 16 de febrero), lo que, en último término, significa que (supuestamente) sigue vigente la Instrucción de 5 de octubre de 2010 (Vilar: 2019, 819-820), pese a su indudable contradicción con la STS de 2014.

Más allá de estas vicisitudes, lo verdaderamente relevante de la referida sentencia del TS, a los efectos que aquí más nos interesan, es que, con independencia de que haya una norma que expresamente ordene que la filiación materna se determina por el parto, el Tribunal considera causa de

${ }^{19}$ Este es uno de los argumentos principales que se utilizan para criticar el sentido de la sentencia tanto en el Voto particular formulado a la misma, como por parte de algunos autores (Presno y Jiménez: 2014). 
inconstitucionalidad la infracción del art. 10 de la Ley 14/2006 por entender que una práctica como la de la gestación por sustitución atenta contra la dignidad de la mujer gestante ${ }^{20}$, garantizada en el art. 10.1 CE, al devaluar a esta como sujeto, para convertirla en un objeto del contrato.

Cabría entender, por tanto, que los límites de la dignidad de la mujer no dependerían de su (autonomía de la) voluntad, sino que, por el contrario, derivarían de la exigencia de respetar el orden público constitucionalmente reconocido. Y es que la dignidad, además de ser el fundamento último de todos los derechos, representa también un límite para el ejercicio de los mismos (Alegre: 1996, 75). Desde el punto de vista del Estado, la cuestión, por tanto, no es si el mismo tiene capacidad para intervenir en ese proceso más allá de la voluntad de las partes, sino que a lo que habrá que atender es a cuál debe ser el límite del Estado a la hora de determinar las consecuencias que la celebración de dicho contrato en un país extranjero puede tener en España, teniendo en cuenta no solo que hay un menor cuyo interés superior merece la máxima protección ${ }^{21}$.

\section{VI.CONCLUSIONES}

A través de todos los ejemplos que acabamos de ver se pone de relieve la imperiosa necesidad de una regulación internacional que ofrezca seguridad jurídica a los casos de gestación por sustitución que se están produciendo en diversos lugares del mundo en los que tal práctica se encuentra aceptada y regulada y en los que intervienen personas nacionales de los mismos (las mujeres gestantes) junto con otras (comitentes) procedentes de terceros

${ }^{20}$ De otra opinión, Manuel Atienza, para quien el Tribunal Supremo no ha comprendido correctamente el concepto de dignidad humana, que, en este caso, lo que prohibiría es tratar a la mujer gestante solamente como un medio o instrumento para conseguir un fin, lo que en su opinión no tiene por qué suceder en los contratos de gestación por sustitución (Atienza: 2015). Desde una posición crítica, Ana Marrades se pregunta «como qué otra cosa se trata a una mujer que gesta para otra persona o personas sino como un medio para satisfacer los deseos de las personas que le hacen el encargo a la gestante, es decir, como un instrumento, y sólo como un instrumento» (Marrades: 2017, 223).

${ }^{21}$ Pilar Benavente se ha mostrado muy crítica con la vacilante respuesta (normativa, judicial y administrativa) que ha dado el Estado español a un tema tan fundamental como lo es el reconocimiento de la filiación de aquellos menores que hayan nacido en un país extranjero como consecuencia de un proceso de gestación por sustitución, y pretendan ser inscritos en España. Una respuesta -según esta autora- claramente discriminatoria si se compara con la otorgada en otros supuestos de determinación de la filiación (Benavente: 2020). Por su parte, Javier Nanclares ofrece una visión diferente del problema, pues, en su opinión, se ha de diferenciar entre el interés superior del menor y el reconocimiento de efectos jurídicos en España a aquellas certificaciones registrales procedentes de otros países en los que esta práctica se encuentra legalizada (Nanclares: 2020). 
países en los que dicha práctica se encuentra prohibida, o es nula de pleno derecho, como es el caso de España (Vilar: 2019, 823) ${ }^{22}$.

Una respuesta jurídico-internacional que, sin perder nunca de vista el interés superior del menor, además debería tener en cuenta, como se ha señalado ya, otros muchos factores, y, en particular, uno que resulta decisivo: que el hecho de que dicha práctica se encuentre prohibida o sea considerada nula de pleno derecho en ciertos países necesariamente ha de jugar un papel importante a la hora de resolver cada caso concreto.

Dicho de otro modo: el interés superior del menor no puede convertirse en una «cómoda» invocación para acabar resolviendo conflictos que demandan, por el contrario, un análisis mucho más detenido y ponderado de todos los bienes, principios y derechos en juego. $\mathrm{Y}$ eso es algo que tanto los tribunales internacionales (en particular, el TEDH) como los tribunales nacionales habrían de tener siempre presente, pues al fin y al cabo, si nos centramos en España, todo nacional que acude a esta práctica en el extranjero es consciente de que la misma es nula de pleno derecho en su país, y que eso, lógicamente, puede tener consecuencias a la hora de pretender la inscripción registral correspondiente, sin que quepa legítimamente esperar que la situación acabará solventándose gracias, simplemente, a una genérica invocación al interés superior del menor.

Dicho de otro modo, la común apelación al interés superior del menor no puede convertirse en una especie de patente de $\operatorname{corso}^{23}$ que permita acabar legalizando indiscriminadamente relaciones jurídicas que han nacido de una actuación ilegal (Durán: 2012, 275). Es decir, en la determinación de lo que en cada caso concreto sea el interés superior del menor no deberíamos de perder nunca de vista esa circunstancia, que no es en absoluto baladí. Al fin y al cabo, lo que puede estar en juego es algo tan fundamental como aquello a lo que se enfrenta la Convención de la ONU sobre la eliminación de todas las

${ }^{22}$ En este sentido, el profesor Javier Matia se muestra partidario de una regulación de esta práctica en España, porque «[d]esde una perspectiva general, resulta absurdo no regular lo que está ocurriendo. Es tanto como desconocer la realidad». Y es que «la función del Derecho es, a nuestro modesto entender, regular las relaciones sociales, canalizándolas y delimitándolas. Luego los justiciables decidirán si se sirven o no de ellas. Solamente aquellas que producen un rechazo social muy mayoritario o protejan derechos fundamentales deben ser proscritas» (Matia: 2019, 111 y 114). El problema es que, en mi opinión, es precisamente este el punto en el que nos encontramos, pues, como he tratado de demostrar a lo largo de este trabajo, la dignidad y los derechos de la mujer gestante se la juegan con la legalización de esta práctica

${ }^{23} \mathrm{O}$, como ha señalado acertadamente el Tribunal Supremo,»[1]a aplicación del principio de la consideración primordial del interés superior del menor ha de hacerse para interpretar y aplicar la ley y colmar sus lagunas, pero no para contrariar lo expresamente previsto en la misma (STS 247/2014, de 6 de febrero, FD Quinto.6). 
formas de discriminación contra la mujer, de 18 de diciembre de 1979, que en su art. 6 conmina a los Estados parte a adoptar las medidas precisas para suprimir todas las formas de trata de mujeres, cosa que -según parece- está sucediendo ya en algunos lugares del mundo en que se permite la gestación para otro/s.

A la espera de que eso suceda, a nivel nacional la solución, como hemos visto, no es sencilla, ni puede ser de alcance general. Lo que no obsta para que sí se pueda, y deba, exigir a las autoridades españolas (administrativas y judiciales) que valoren de manera detenida todas las circunstancias que concurran en cada caso que se les presente a partir de una certeza: que el contrato de gestación para otro/s celebrado en una país extranjero por nacionales españoles del que trae causa la maternidad/paternidad del bebé que pretenden inscribir en el registro español correspondiente como hijo suyo es en España nulo de pleno derecho, y que, en principio, eso constituye un importante impedimento que solo se podrá vencer si queda suficientemente acreditado que, dadas las circunstancias, el interés superior del menor debe de prevalecer (porque, destacadamente, existan lazos biológicos de este con alguno de los comitentes y/o porque la convivencia entre ellos se haya prolongado durante un largo período de tiempo). El mensaje, en todo caso, debería de ser bien claro: aquel nacional español que acuda a esta práctica en el extranjero ha de saber que está asumiendo un riesgo muy elevado de que al llegar a España con el bebé no pueda inscribirlo como hijo suyo. La última sentencia del TEDH de 24 de enero de 2017, en el caso Paradiso Campanelli c. Italia, matizaciones al margen, parece apuntar en esa dirección, sobre todo, cuando no exista vínculo genético alguno entre los comitentes y el menor, en la medida en que Tribunal acepta que el margen de apreciación nacional es muy amplio en una cuestión como esta en la que se dilucidan cuestiones muy sensibles para las opiniones públicas internas de los respectivos Estados parte (García Roca: 2018, 3).

En definitiva, cada caso concreto debe de ser objeto de un análisis detenido, en el que se tengan en cuenta todas las circunstancias, evitando soluciones de alcance general derivadas de la aplicación automática de un principio (el interés superior del menor o el orden público internacional), por muy relevante que sea, pues eso es lo que demanda una aplicación seria y prudente del derecho.

\section{BIBLIOGRAFIA}

Alberti, A. (2020). «La maternità surrogata in Italia», Revista General de Derecho Constitucional, 31

Alcaraz, H. (2020). «La gestación subrogada en Francia: paradojas y restricciones», Revista General de Derecho Constitucional, 31 
Alegre Martínez, M. Á. (1996). La dignidad como fundamento del ordenamiento constitucional español, Universidad de León

Arroyo GIL, A. (2017). “'Gestación subrogada' versus 'vientres de alquiler'», Huffington Post (21.02.2017)

AtienZA, M. (2006). «Reproducción Humana Asistida: sobre la nueva ley», El Notario del Siglo XXI, 9

— (2015). «Gestación por sustitución y prejuicios ideológicos», El Notario del Siglo XXI, 63

Balaguer Callejón, M. L. (2017).Hij@s del mercado, Cátedra, Madrid

Benavente Moreda, P. (2020). «El interés superior de los menores nacidos a partir de un contrato de gestación por sustitución», Revista General de Derecho Constitucional, 31 .

Brunet, L. (Dir.) (2013). A Comparative Study on the Regime of Surrogacy in EU Member States, European Parliament

Carmona Cuenca, E. / Redondo Saceda, L. (2020). «La gestación por sustitución en la jurisprudencia del Tribunal Europeo de Derechos Humanos», Revista General de Derecho Constitucional, 31

Calvo Caravaca, A.-L. / Carrascosa González, J. (2015). «Gestación por sustitución y Derecho internacional privado. Más allá del Tribunal Supremo y del Tribunal Europeo de Derechos Humanos»), Cuadernos de Derecho Transnacional, 7 (2)

Chuecha, R. (2015). «La marginalidad jurídica de la dignidad humana», en Chueca, R. (Dir.), Dignidad humana y derecho fundamental, CEPC, Madrid

Díaz Crego, M. (2020). «La posición de los comitentes en el debate en torno a la gestación por sustitución: a las vueltas con el supuesto derecho a tener hijos», Revista de Derecho Constitucional, $\mathrm{n}^{\mathrm{o}} 31$.

DíAz Romero, M.R. (2010). «La gestación por sustitución en nuestro ordenamiento jurídico». Diario La Ley, 7527

Durán Ayago, A. (2012). «El acceso al Registro Civil de certificaciones registrales extranjeras a la luz de la ley 20/2011: relevancia para los casos de filiación habida a través de gestación por sustitución», Anuario español de derecho internacional privado, 12

— (2019). «Gestación por sustitución en España: A hard case needs law. De por qué la jurisprudencia no puede resolver este problema», Cuadernos de Derecho Transnacional, 11 (2)

Elvira Perales, A. (2015). «La dignidad humana en el Tribunal Europeo de Derechos Humanos», en Chueca, R. (Dir.), Dignidad humana y derecho fundamental, CEPC, Madrid

FARNÓs AMORÓs, E. (2015) «La filiación derivada de la reproducción asistida: voluntad y biología», Anuario de Derecho Civil del Ministerio de Justicia, 68

— (2017). «Paradiso y Campanelli c. Italia (II): los casos difíciles crean mal derecho», Revista de Bioética y Derechos, 40

García Roca, J. (2018). «La transformación del Convenio Europeo de Derechos Humanos», Revista General de Derecho Constitucional,28.

GómEZ FERNÁNDEZ, I. (2020). «Incertidumbres y algunas certezas sobre la gestación subrogada en Portugal: descripción normativa y respuestas jurisprudenciales», Revista General de Derecho Constitucional, 31 
Gómez SÁnchez, Y. (1994). El derecho a la reproducción humana, Marcial Pons, Madrid

(2005). «Dignidad y ordenamiento comunitario», Revista de Derecho Constitucional Europeo, n4.

LAMм, E. (2013). Gestación por sustitución. Ni maternidad subrogada ni alquiler de vientres, Universitat de Barcelona: Publicacions i Edicions.

LORA, P. de (2018): «Gestar para otros: una ecografía de las falacias», Dilemata (Revista Internacional de Éticas Aplicadas), 28

Marrades Puig, A. (2017). «La gestación subrogada en el marco de la Constitución española: una cuestión de derechos», Estudios de Deusto, 65/1

Matia Portilla, F.J. (2019). «¿Resulta oportuno dar un tratamiento jurídico a la gestación subrogada en nuestro país?», Revista de Derecho Político, 105.

NANClaRes VAlle, J. (2020). «El interés superior del menor en la gestación por sustitución». Revista General de Derecho Constitucional, 31

Presno Linera, M.A / Jimenez Blanco, P. (2014). «Libertad, igualdad, ¿maternidad? La gestación por sustitución y su tratamiento en la jurisprudencia», Revista Española de Derecho Europeo, 51.

Quicios Molina, S. (2019). «Regulación por el ordenamiento español de la Gestación por sustitución: dónde estamos y hasta dónde podemos llegar», Revista de Derecho Privado, 1

REDONDO SACEDA, 1. (2020). «Gestación por sustitución y reconocimiento de la filiación en Europa: reflexiones a la luz del Convenio Europeo de Derechos Humanos»), Revista General de Derecho Constitucional, 31

Rodríguez Ruiz, B. (2017). «¿Identidad o autonomía? La autonomía relacional como pilar de la ciudadanía democrática», Anuario de la Facultad de Derecho de la Universidad Autónoma de Madrid, 17

Ruiz Martín, A. M. (2019). «El caso Campanelli y Paradiso ante el Tribunal Europeo de Derechos Humanos: el concepto de familia de facto y su aportación al debate de la gestación por sustitución», Cuadernos de Derecho Transnacional, 11 (2)

Ruiz-Rico Ruiz, G. (2017). «La problemática constitucional derivada de las Técnicas de Reproducción Humana Asistida (TRHA): el caso de la maternidad subrogada», Revista de Derecho Político, 99

SAlazar Benítez, O. (2017). «La gestación por sustitución desde una perspectiva jurídica: algunas reflexiones sobre el conflicto entre deseos y derechos», Revista de Derecho Político, 99

- (2018). La gestación para otros: una reflexión jurídico-constitucional sobre el conflicto entre deseos y derechos, Dykinson, Madrid

- (2020) «La autonomía de las mujeres en juego: la gestación para otros desde una perspectiva de género», Revista General de Derecho Constitucional, 31

SIMÓN YARZA, F. (2017). «Gestación subrogada o vientres de alquiler: reflexiones a la luz del derecho comparado y de la jurisprudencia del Tribunal Europeo de Derechos Humanos», Revista General de Derecho Constitucional, 25

- (2020). «El debate sobre los vientres de alquiler, los derechos humanos y el bien común», Revista General de Derecho Constitucional, 31

ÚbedA DE TORRES, A. (2020). «Un análisis de la legislación de California sobre la gestación por sustitución», Revista General de Derecho Constitucional, 31 
Valero Heredia, A. (2019). «La maternidad subrogada: un asunto de derechos fundamentales», Teoría y Realidad Constitucional, 43

Vela SÁnchez, A. J. (2015). Gestación por encargo: tratamiento judicial y soluciones prácticas. La cuestión jurídica de las madres de alquiler, Reus, Madrid

VERONESI, P. (2015). «La dignidad humana: una idea aparentemente clara. Entre la tópica y la hermenéutica constitucional italiana», Chueca, R. (Dir.), Dignidad humana y derecho fundamental, CEPC, Madrid

VILAR GómEZ, S. (2018). La gestación subrogada en España y en el derecho comparado, Wolters Kluwer, Madrid

(2019). «La inseguridad jurídica derivada de la insuficiente regulación de la gestación subrogada en España», Cuadernos de Derecho Transnacional, 11 (2) 


\title{
GESTACIÓN POR SUSTITUCIÓN: LA DIGNIDAD HUMANA EN JUEGO
}

\author{
Gestational surrogacy: human dignity at stake
}

\author{
Antonio Arroyo Gil \\ Profesor Ayudante Doctor (acr. Titular) de Derecho constitucional \\ Universidad Autónoma de Madrid \\ antonio.arroyo@uam.es
}

http://dx.doi.org/10.18543/ed-68(2)-2020pp41-73

\section{Copyright}

Estudios de Deusto es una revista de acceso abierto, lo que significa que es de libre acceso en su integridad. Se permite su lectura, la búsqueda, descarga, distribución y reutilización legal en cualquier tipo de soporte sólo para fines no comerciales, sin la previa autorización del editor o el autor, siempre que la obra original sea debidamente citada y cualquier cambio en el original esté claramente indicado

Estudios de Deusto is an Open Access journal which means that it is free for full access, reading, search, download, distribution, and lawful reuse in any medium only for non-commercial purposes, without prior permission from the Publisher or the author; provided the original work is properly cited and any changes to the original are clearly indicated. 